\title{
Short communication: Survival of replacement kids from birth to mating on commercial dairy goat farms in New Zealand
}

\author{
C. G. Todd, ${ }^{1,2}$ B. Bruce, ${ }^{1}$ L. Deeming, ${ }^{1,2}$ and G. Zobel ${ }^{1 *}$ \\ ${ }^{1}$ AgResearch Limited, Animal Welfare Team, Hamilton 3214, New Zealand \\ ${ }^{2}$ Massey University, Palmerston North 4442, New Zealand
}

\section{ABSTRACT}

Commercial dairy goat systems rely on the successful rearing of kids for herd replacement. The objectives of this study were to (1) determine survival from birth until mating for a large cohort of commercial dairy goat kids; (2) descriptively summarize the causes of mortality and removal from the herd during this period; and (3) compare actual (determined by postmortem examination) and suspected (farmer-reported) causes of mortality. A total of 1,262 female kids were enrolled at birth on 16 commercial dairy goat farms in New Zealand. Median ages at weaning and mating were $86 \mathrm{~d}[$ minimum $=54$, quartile $(\mathrm{Q}) 1=78, \mathrm{Q} 3=97$, maximum $=144]$ and 223 $\mathrm{d}($ minimum $=183, \mathrm{Q} 1=208, \mathrm{Q} 3=237$, maximum $=310)$, respectively. Overall, $87.1 \%(1,099 / 1,262)$ of kids remained on farm at mating, $10.4 \%(131 / 1,262)$ died or were euthanized, and $2.5 \%(32 / 1,262)$ were lost to follow-up or sold. Mortality risk was greatest in early life, with more than $90 \%$ of deaths occurring before weaning. Mortality from enrollment to mating varied between farms (minimum $=0 \%, \mathrm{Q} 1=5.9 \%$, median $=8.9 \%, \mathrm{Q} 3=15.8 \%$, maximum $=20.5 \%$ ). The leading cause of death was gastrointestinal disorders (33.6\%, 36/107), followed by disbudding-related injury $(15.9 \%, 17 / 107)$, and septicemia $(12.1 \%, 13 / 107)$. Farmers correctly identified approximately half of the deaths attributed to gastrointestinal disorders $(56.0 \%$, $14 / 25)$ and disbudding-related injury $(44.4 \%, 4 / 9)$, but were less successful at diagnosing septicemia $(0 \%, 0 / 5)$, starvation or dehydration $(0 \%, 0 / 4)$, and suffocation $(18.8 \% 3 / 16)$. This is the largest cohort of dairy goat kids to be systematically followed over time to confirm survival until mating and to determine causes of death by postmortem examination. We found that kid mortality was highest during the preweaning period and there was often a discrepancy between farmer-perceived and actual cause of death. Postmortem examinations

Received January 8, 2019.

Accepted May 13, 2019.

*Corresponding author: gosia.zobel@agresearch.co.nz should be more widely used to establish causes of death and inform on-farm strategies to reduce kid mortality. Key words: caprine, mortality, gastrointestinal disorders, disbudding, septicemia

\section{Short Communication}

Replacement kids that die or are removed from the herd before they begin lactating represent an economic loss to the farm and industry. Mortality is also an important farm-level indicator of animal welfare (OrtizPelaez et al., 2008; de Vries et al., 2011). Dairy goat farmers in the United States estimated that $13.3 \%$ of all kids born during 2015 died during the same calendar year (USDA, 2017); these data do not distinguish between stillbirth and mortality in kids born alive. In New Zealand, more than half of goat carcasses submitted to an animal health laboratory for postmortem examination were of animals younger than 6 mo of age (Buddle et al., 1988). Gautam (2012) summarized removal records from 38 commercial dairy goat farms in New Zealand and reported that within the first year of life, on any given day, more than 6 goats were removed because of death, culling, or sale.

Causes of mortality and other reasons for removal from the herd have not been well documented in dairy goat kids. Miscellaneous disorders, such as bloat, gastrointestinal issues, cancer, and other non-infectious causes, were cited by dairy goat farmers in New Zealand as the main removal reasons, but these data were not stratified by age category, so kid and adult removals were summarized together (Gautam, 2012). Goat farmers in the United States identified internal parasites and weather-related problems as the leading causes of kid mortality, yet they were unable to determine a suspected cause of death in almost $30 \%$ of cases (USDA, 2017). That survey did not stratify by use type and thus included causes of mortality from all farm systems (i.e., milk, meat, and fiber production).

Postmortem examination is an important diagnostic tool for establishing cause of death or resolving unclear cases (McConnel et al., 2009; Thomsen et al., 2012; Wäsle et al., 2017). In extensively managed goat 
herds, postmortem examinations have indicated that mis-mothering, hypothermia, white muscle disease, and enteritis are key causes of kid death (Buddle et al., 1988; Ramírez-Bribiesca et al., 2001). Although those authors did not compare their findings with farmer reports, research in other species has demonstrated potential discrepancies between postmortem diagnoses and farmer-suspected causes of death (McConnel et al., 2009; Thomsen et al., 2012). The objectives of this study were to (1) determine survival from birth until mating for a large cohort of commercial dairy goat kids, (2) descriptively summarize the causes of mortality and removal from the herd during this period, and (3) compare actual (determined by postmortem examination) and suspected (farmer-reported) causes of mortality.

All study procedures were approved by the AgResearch Limited Human (\#6/2015) and Animal Ethics Committees (\#13478). Sixteen commercial dairy goat farmers from the Waikato region of New Zealand volunteered to participate. Selection was based on farmer willingness to participate, and no prescreening of farm management occurred. The Waikato region contains $72 \%$ of New Zealand's dairy goat farms (Scholtens et al., 2017); these farms are predominantly members of the Dairy Goat Cooperative. The enrolled farms represented $22 \%$ of all Cooperative farms. Lactating herd size $[$ minimum $=343$; quartile $(\mathbf{Q}) 1=572$, median $=636, \mathrm{Q} 3=849$, maximum $=1,539]$ and mean milk production (test-day total milk, $\mathrm{kg} /$ doe: minimum $=2.9, \mathrm{Q} 1=3.3$, median $=3.6, \mathrm{Q} 3=3.9$, maximum $=$ 4.5; milk fat, \%: minimum $=3.2, \mathrm{Q} 1=3.5$, median $=$ 3.6, Q3 = 3.7, maximum $=4.0$; protein, $\%$ : minimum $=2.9, \mathrm{Q} 1=3.0$, median $=3.1, \mathrm{Q} 3=3.2$, maximum $=$ 3.3) for each enrolled farm were estimated using 2017 herd test data (Livestock Improvement Corporation, Hamilton, New Zealand). Herd test data were not available for 3 farms. Farmers reported that they intended to rear between 90 and 500 replacement kids $(\mathrm{Q} 1=$ 175 , median $=250, \mathrm{Q} 3=300)$ during 2015 . To minimize the likelihood of selection bias (e.g., farmers enrolling only their healthiest animals), kids were enrolled immediately after birth. A total of 1,262 female kids were enrolled between May 26 and September 5, 2015, which coincided with the typical winter kidding season in New Zealand (Scholtens et al., 2017). The majority of kids were born in July $(63.5 \%, 802 / 1,262)$, followed by June $(21.9 \%, 276 / 1,262)$, August $(7.8 \%, 99 / 1,262)$, May $(6.2 \%, 78 / 1,262)$, and September $(0.6 \%, 7 / 1,262)$. The median number of enrolled kids per farm was 80 $($ minimum $=70, \mathrm{Q} 1=79, \mathrm{Q} 3=80$, maximum $=83)$, and median age at enrollment was $1 \mathrm{~d}$ of age (minimum $=1, \mathrm{Q} 1=1, \mathrm{Q} 3=2$, maximum $=8$ ). Two additional kids were enrolled and subsequently excluded from all analyses when confirmed to be male. To track individ- ual kids over time, the farm identifier for each kid was printed on a yellow cow ear tag (Maxi Tag, Allflex NZ Ltd., Palmerston North, New Zealand) and attached to their orange collar. All kids were also assigned with a unique identification number for the study.

Kids were cared for according to standard farm protocols; no experimental treatments or interventions were applied by the research team. After removal from the dam (immediately on 4 farms, up to $24 \mathrm{~h}$ on 11 farms, after $24 \mathrm{~h}$ on 1 farm), colostrum was fed (heat-treated goat colostrum on 2 farms, untreated goat colostrum on 5 farms, untreated cow colostrum on 5 farms, bovinebased replacer on 2 farms, and no additional colostrum on 2 farms where kids remained with the dam for $24 \mathrm{~h}$ or longer). Kids were housed in all-female group pens (enrolled kids mixed with nonenrolled kids) and had access to ad libitum whole cow milk (on 2 farms) or milk powder (whole milk on 8 farms; whey-based on 6 farms) for at least part of the preweaning period. Kids were disbudded within the first few weeks of life, using cautery methods (15 farms) or caustic paste (1 farm). A nonsteroidal anti-inflammatory drug (NSAID) was administered following cautery disbudding on 1 farm. Decision criteria for weaning were BW (11 farms), age (2 farms), or a combination of BW and age (3 farms). Minimum target age for weaning varied from 8 to 10 wk. Farmers favoring BW for weaning decisions reported a minimum weight of $15 \mathrm{~kg}$; however, only 2 farmers routinely weighed their kids. All farms used natural mating and farmers aimed to introduce bucks between 7 and 8 mo. of age.

Farmers were responsible for daily kid care, detecting and administering treatment for illness, and documenting dates and reasons for removal from the herd. Removal reasons included death, euthanasia, lost to follow-up (e.g., due to an identification issue, movement off-site, or inability to determine whereabouts of kid), or sold. If the farmer did not provide a removal date for a kid that was no longer in the herd, removal date was assigned as $1 \mathrm{~d}$ after the last confirmed presence on the farm. Confirmation was based on health treatment records or weighing records collected by the research team during routine farm visits. Farmers were asked to submit dead kids for postmortem examination; when possible, the farmer also provided a clinical history and the suspected cause of death. If the postmortem examination could be performed within $2 \mathrm{~d}$ of death, the carcass was refrigerated at $4^{\circ} \mathrm{C}$; otherwise, it was frozen at $-20^{\circ} \mathrm{C}$ and thawed for $1 \mathrm{~d}$ before the examination. A systematic inspection of all thoracic and abdominal organs, tissues, joints, umbilicus, skull, and brain was completed by a veterinarian. Cause of death was determined based on any gross pathological lesions or abnormal findings observed. Histopathology was 
not performed. Sudden death and no obvious cause of death on gross examination were classified as suspected Clostridial infection; diagnostic laboratory testing was not completed to confirm the diagnosis.

Data were analyzed using SAS 9.4 (SAS Institute Inc., Cary, NC), with goat kid as the unit of interest. A Kaplan-Meier curve was constructed to display cumulative survival to mating (PROC LIFETEST). Kids that were removed from the herd before mating because of death, euthanasia, or other reason (e.g., lost to follow-up or sold) were treated as censored observations. Descriptive statistics were generated for age at enrollment, censoring, weaning, and mating (PROC UNIVARIATE). Survival, causes of death and reasons for removal from the herd were summarized across 3 periods: (1) enrollment to $14 \mathrm{~d}$ of age, (2) $15 \mathrm{~d}$ to weaning, and (3) weaning to mating (PROC FREQ). Survival and removals from the herd were summarized by farm. A contingency table (PROC FREQ) was used to compare postmortem-determined and suspected causes of death.

This study followed a large cohort of dairy goat kids under commercial conditions, across multiple farms, to establish survival until mating (Figure 1). A total of 163 kids were removed from their respective herds by mating. Median age at censoring was $30 \mathrm{~d}$ (minimum $=$
$2, \mathrm{Q} 1=7, \mathrm{Q} 3=55$, maximum $=198)$. At $14 \mathrm{~d}$ of age, $95.1 \%(1,200 / 1,262)$ of the enrolled kids remained on farm; of the 62 kids that were removed, 40 died, 12 were euthanized, 6 were lost to follow-up, and 4 were sold. At weaning, $89.2 \%(1,126 / 1,262)$ of the enrolled kids remained on farm. Of the additional 74 kids removed after $14 \mathrm{~d}$ of age, 50 died, 17 were euthanized, and 7 were lost to follow-up. Median age at weaning ( $\mathrm{n}=$ 1,019 kids) was $86 \mathrm{~d}$ (minimum $=54, \mathrm{Q} 1=78, \mathrm{Q} 3=$ 97 , maximum $=144)$. Farmers did not provide weaning dates for 107 kids; however, these kids were confirmed alive at a follow-up visit by the research team. At mating, $87.1 \%(1,099 / 1,262)$ enrolled goats remained on farm. Of the 27 goats removed between weaning and mating, 12 died and 15 were lost to follow-up. Median age $(\mathrm{n}=1,071)$ at mating was $223 \mathrm{~d}$ (minimum $=183$, $\mathrm{Q} 1=208, \mathrm{Q} 3=237$, maximum $=310)$. Farmers did not provide mating dates for 28 goats but these goats were confirmed alive at a follow-up visit.

Overall, 10.4\% $(131 / 1,262)$ of the enrolled kids died or were euthanized between enrollment and mating. All kids had to be alive at enrollment so this estimate does not include stillbirths. Mortality risk in this cohort of dairy goat kids was greatest during the preweaning period (i.e., greater than $90 \%$ of deaths), which confirms that this is a high-risk period for mortality in goat

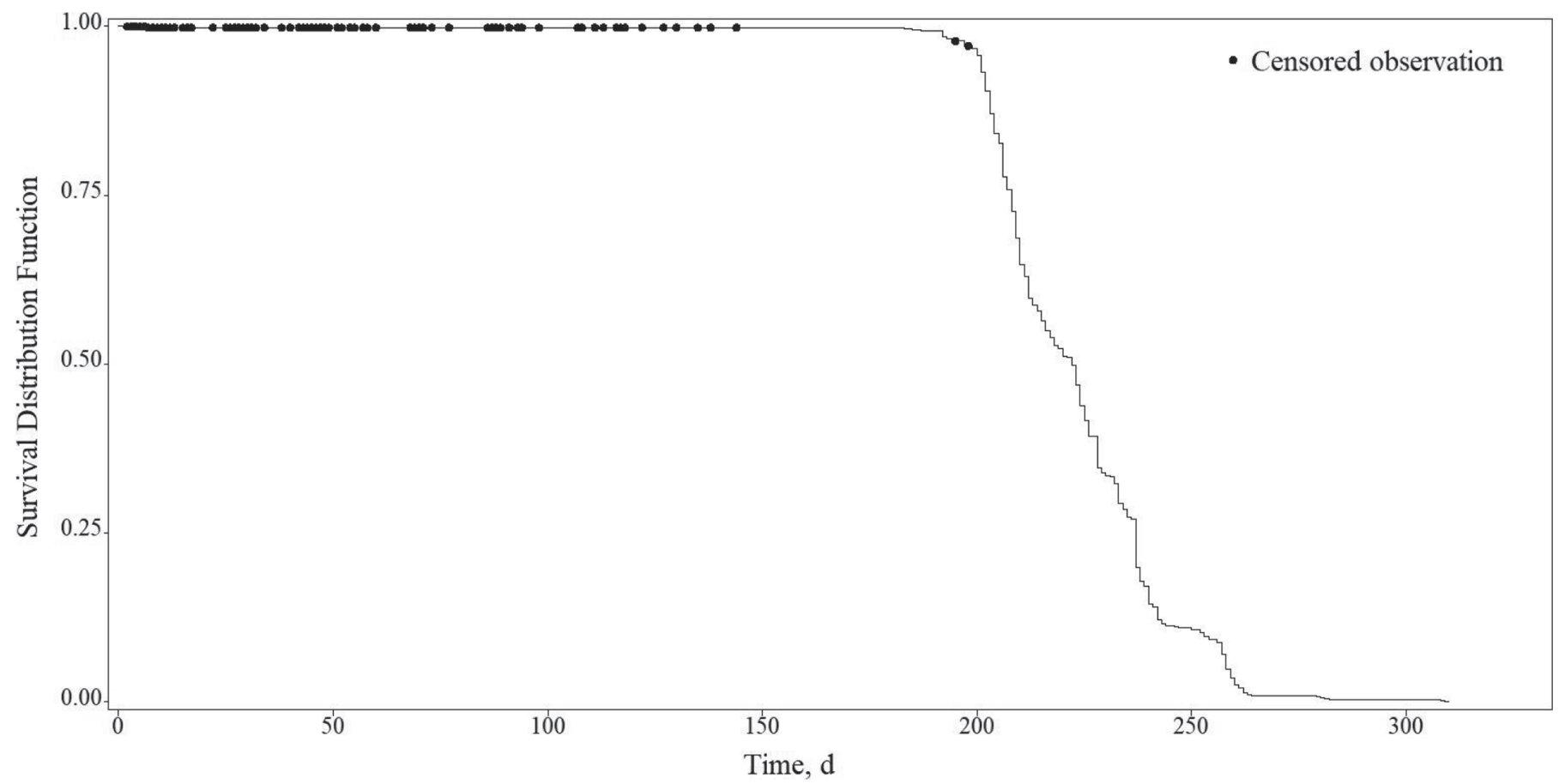

Figure 1. Kaplan-Meier curve for survival from enrollment to mating for 1,262 dairy goat kids on 16 commercial farms. The survival function begins at 1.0, decreases with every kid that was mated, and ultimately reaches 0.0 after all kids had been mated or censored. Censored observations include any kid that died, was euthanized, or was removed from the herd for another reason (e.g., lost to follow-up or sold). Median age at weaning was $86 \mathrm{~d}$ [minimum $=54$, quartile $(\mathrm{Q}) 1=78, \mathrm{Q} 3=97$, maximum $=144]$. Median age at mating was $223 \mathrm{~d}($ minimum $=183$, Q1 $=$ $208, \mathrm{Q} 3=237$, maximum $=310)$. Median age at censoring was $30 \mathrm{~d}($ minimum $=2, \mathrm{Q} 1=7, \mathrm{Q} 3=55$, maximum $=198)$. 


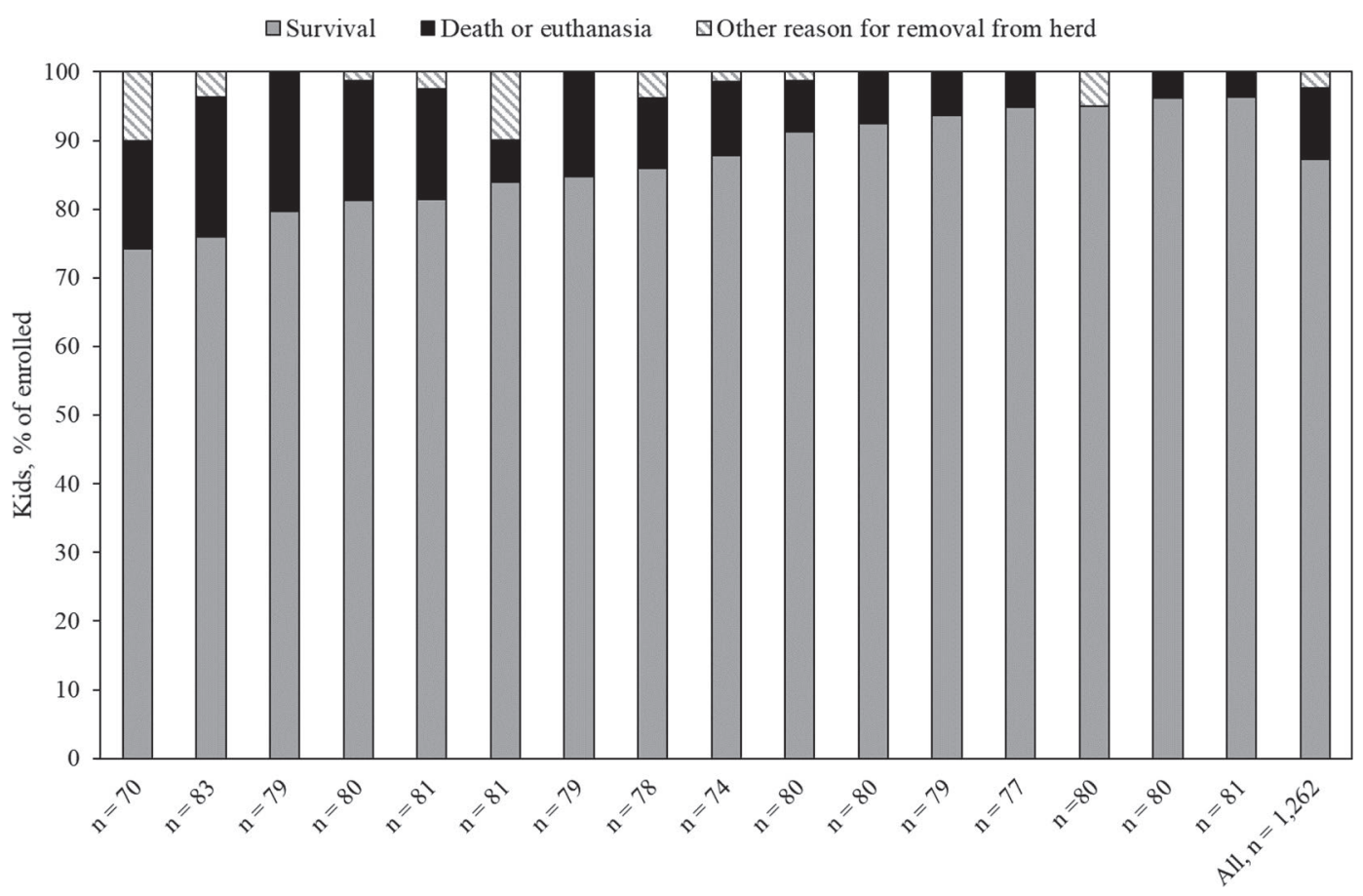

Figure 2. Farm-level distribution of survival, mortality (death or euthanasia), and other reasons for removal from herd (e.g., lost to followup or sold) from enrollment to mating, for 1,262 dairy goat kids on 16 commercial farms, with farms ordered from lowest to highest survival.

kids (Perez-Razo et al., 1998; Turkson, 2003; Snyman, 2010). Goat kid mortality can exceed $40 \%$ in tropical and subtropical areas, where kids are mainly reared under extensive or semi-extensive conditions (Husain et al., 1995; Awemu et al., 1999; Ameh et al., 2000; Snyman, 2010). Farmers in the United States estimated that $10 \%$ of kids born alive on milk-producing farms died before weaning (USDA, 2010). Kids enrolled in the present study were generally from larger herds than those in North America, but management would be relatively similar (e.g., born indoors, reared separately from the dam, fed whole milk or milk replacer; USDA, 2010; Bauman et al., 2016).

Mortality varied by farm (minimum $=0 \%, \mathrm{Q} 1=$ $5.9 \%$, median $=8.9 \%, \mathrm{Q} 3=15.8 \%$, maximum $=$ $20.5 \%$ ). More than $20 \%$ of enrolled kids on 2 farms died or were euthanized between enrollment and mating, whereas no deaths were recorded on another farm (Figure 2). Large between-farm variation in mortality has also been reported in Angora goat kids (Snyman, 2010). Specific animal, environmental, and management factors (e.g., birth weight, colostrum ingestion, sex, twin/triplet status, time spent with the dam, housing, preventive health treatments, or season) can influence kid mortality risk (e.g., Gebrelul et al., 1994; Husain et al., 1995; Awemu et al., 1999; Massimini et al., 2007). Further research should investigate associations between management practices, environmental factors, and farm-level mortality. Future research to evaluate risk factors for mortality is planned.

Of the 131 kids that died or were euthanized, 107 were submitted for postmortem examination (Table 1). Overall, the leading causes of mortality were gastrointestinal disorders $(33.6 \%, 36 / 107)$, including bloat, ruptured abomasum, intestinal torsion, and enteritis, followed by disbudding-related injury $(15.9 \%, 17 / 107)$ and septicemia $(12.1 \%, 13 / 107)$. Of the deaths that occurred during the first $14 \mathrm{~d}$ of life, $18.6 \%(8 / 43)$ and $14.0 \%(6 / 43)$ were due to septicemia and starvation or dehydration, respectively. Of the deaths that occurred after $14 \mathrm{~d}$ of age, $42.2 \%(27 / 64)$ and $18.8 \%(12 / 64)$ were attributed to gastrointestinal disorders and disbuddingrelated injury, respectively.

Although gastrointestinal disorders are a significant cause of mortality in young ruminants (e.g., Vatn et al., 2000; Urie et al., 2018), we had not expected that abomasal rupture or intestinal torsion would result in 1 of every 4 deaths $(26.2 \%, 28 / 107)$. The exact pathogeneses of these conditions are not fully understood (Marshall, 2009; Pugh and Baird, 2012; Burgstaller et al., 2017), but associations with farm-specific feeding management are likely. Deaths due to abomasal rupture were generally the result of bloat; only 1 case of perforated abomasal ulcer was recorded. More than two-thirds of the farms $(68.8 \%, 11 / 16)$ had at least one gastrointestinal disorder death. Interestingly, half of all deaths due 
Table 1. Causes of mortality as determined by postmortem examination for 107 dairy goat kids that died or were euthanized between enrollment and mating on 16 commercial farms

\begin{tabular}{|c|c|c|c|c|}
\hline Primary cause $^{1}$ & $\begin{array}{l}\text { Birth to } \\
14 \mathrm{~d}, \text { no. }\end{array}$ & $\begin{array}{c}15 \mathrm{~d} \text { to } \\
\text { weaning, }{ }^{2} \text { no. }\end{array}$ & $\begin{array}{l}\text { Weaning to } \\
\text { mating, }{ }^{3} \text { no. }\end{array}$ & Total, no. \\
\hline Ruptured abomasum & 3 & 14 & 1 & 18 \\
\hline Disbudding-related injury & 5 & 12 & - & 17 \\
\hline Septicemia & 8 & 5 & - & 13 \\
\hline Intestinal torsion & 2 & 7 & 1 & 10 \\
\hline Pneumonia & 2 & 5 & 2 & 9 \\
\hline Suspected Clostridia infection & 1 & 6 & 1 & 8 \\
\hline Starvation or dehydration & 6 & - & - & 6 \\
\hline Suffocation $^{4}$ & 5 & - & - & 5 \\
\hline Enteritis & 2 & 3 & - & 5 \\
\hline Bloat & 2 & - & 1 & 3 \\
\hline Joint ill & 1 & 1 & - & 2 \\
\hline Brain hemorrhage & 2 & - & - & 2 \\
\hline Congenital deformity & 1 & 1 & - & 2 \\
\hline Injury & - & 1 & - & 1 \\
\hline Unknown $^{5}$ & 3 & 3 & - & 6 \\
\hline Total $^{6}$ & 43 & 58 & 6 & 107 \\
\hline
\end{tabular}

${ }^{1}$ Causes of mortality are reported in order of total frequency, with ruptured abomasum being the most frequent and injury being the least frequent.

${ }^{2}$ Median age at weaning was $86 \mathrm{~d}$ (minimum $=54$, quartile $1=78$, quartile $3=97$, maximum $\left.=144\right)$.

${ }^{3}$ Median age at mating was $223 \mathrm{~d}$ (minimum $=183$, quartile $1=208$, quartile $3=237$, maximum $=310$ ).

${ }^{4}$ Referred to as "smothered" by farmers.

${ }^{5}$ No cause of death was determined during postmortem examination.

${ }^{6} \mathrm{~A}$ total of 131 kids died; however, 24 kids were not submitted for postmortem examination.

to gastrointestinal disorder occurred on just 2 farms. Of those kids that died of gastrointestinal disorders, $66.7 \%(24 / 36)$ were fed using automated milk feeders and $33.3 \%(12 / 36)$ were fed from large drums with multiple teats. Overall, $55.7 \%(703 / 1,262)$ and $44.3 \%$ $(559 / 1,262)$ of enrolled kids were reared on automated and drum-based feeders, respectively. Whole milk powder was fed to $72.2 \%(26 / 36)$ of kids that died of gastrointestinal disorders, whereas whey-based powder $(19.4 \%, 7 / 36)$ or whole cow milk $(8.3 \%, 3 / 36)$ was fed to the other kids. Overall, whole milk powder, wheybased powder, and whole cow milk were fed to $50.2 \%$ (634/1,262), 37.0\% (467/1,262), and 12.8\% (161/1,262) of enrolled kids, respectively. We encourage future work to focus on farm-specific feeding practices (e.g., milk preparation routine, cleaning procedures, feeder competition, individual intake), paired with laboratory testing for pathogen identification (Vaatstra, 2018).

Disbudding causes considerable tissue damage and inflammation (Thompson et al., 2005; Hempstead et al., 2018b), and wounds can take months to heal and re-epithelialize (Adcock and Tucker, 2018; Hempstead et al., 2018a). Cautery disbudding in goat kids, when performed incorrectly, can cause thermal injury to the skull and brain (Sanford, 1989; Thompson et al., 2005; Dennler et al., 2014; Hempstead et al., 2018b). Compared with calves, goat kids are at increased risk of thermal injury because their frontal bone is relatively thin, horn buds are larger, and the frontal sinus is un- developed (Thompson et al., 2005; Molaei et al., 2015). Postmortem examination identified several lesions consistent with disbudding injury, including inflammation and purulent discharge beneath the horn bud site, discoloration on the inner surface of the skull, reddened meninges, and meningitis. Age at death for kids that died of disbudding-related injury ranged from 2 to 57 $\mathrm{d}(\mathrm{Q} 1=13$, median $=28, \mathrm{Q} 3=38)$. Six kids showed signs of other conditions (e.g., pneumonia, scouring) at postmortem examination; however, presence of meningitis, infection below the horn buds, burns on the underside of the skull, or brain discoloration was determined to be primary cause of death. More than half of the participating farms $(56.3 \%, 9 / 16)$ had at least one death attributed to disbudding-related injury. Of the kids that died of disbudding-related injury, $47.1 \%$, $(8 / 17)$ were on farms where disbudding was performed by farm staff; the other kids were disbudded by the herd veterinarian $(29.4 \%, 5 / 17)$ or a contractor $(23.5 \%$, 4/17). Collectively, this demonstrates that, regardless of operator experience, implementation of appropriate care and correct disbudding procedure is vital.

Farmers provided a suspected cause of death for 54 of the submitted carcasses (Figure 3). Suspected causes suggested that the majority of the kids died of gastrointestinal disorders $(31.5 \%, 17 / 54)$, suffocation by smothering $(29.6 \%, 16 / 54)$, pneumonia $(11.1 \%, 6 / 54)$, or disbudding-related injury $(9.3 \%, 5 / 54)$. Overall, there was a lack of agreement between actual and sus- 


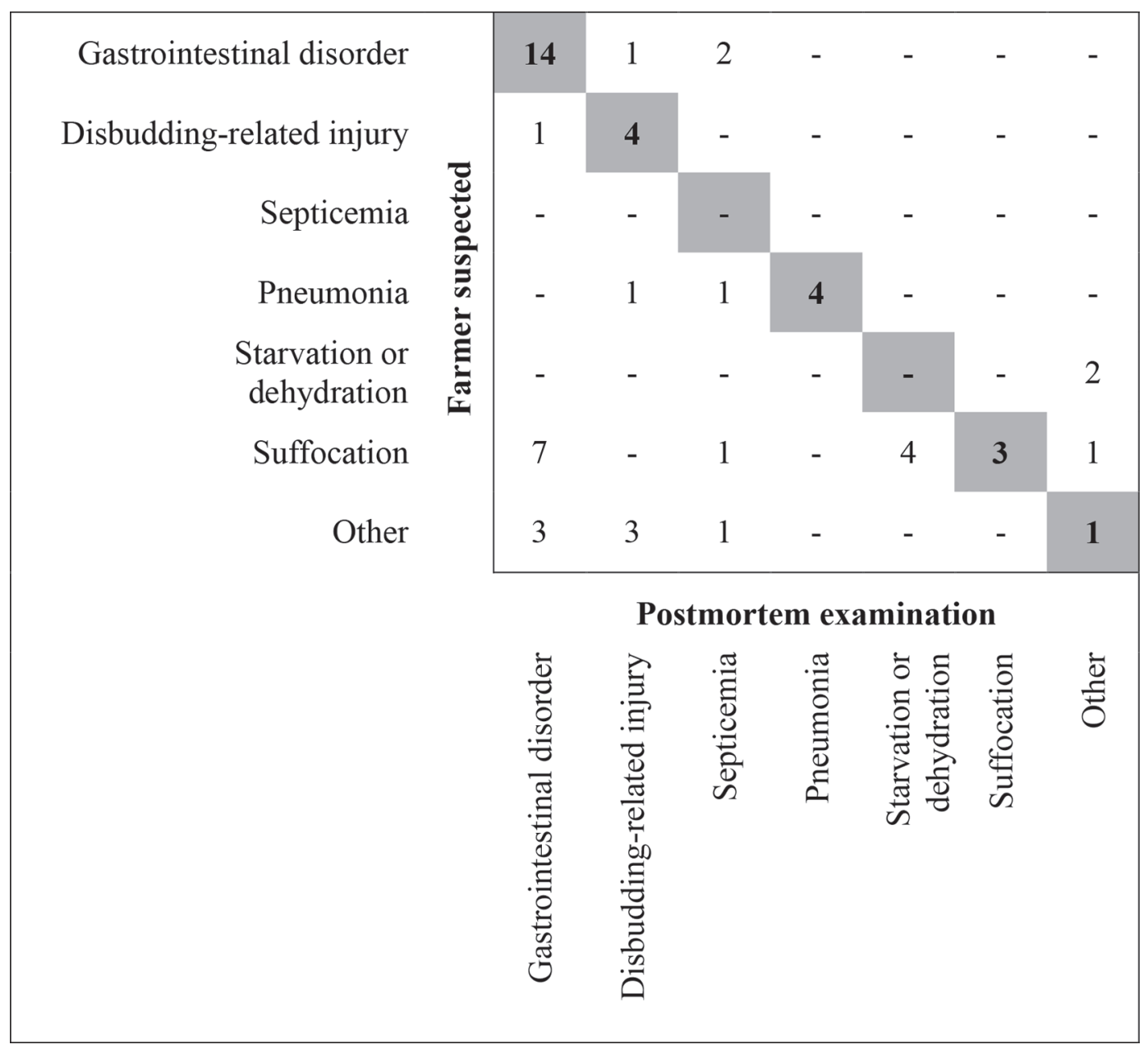

Figure 3. Causes of mortality for 54 dairy goat kids that died or were euthanized between enrollment and mating presented as a comparison between postmortem examination-determined causes and farmer-suspected causes. Shaded cells display the number of suspected causes of death provided by farmers that were subsequently confirmed by postmortem examination. "Gastrointestinal disorder" includes deaths due to bloat, ruptured abomasum, intestinal torsion, and enteritis. "Other" includes deaths due to suspected Clostridia infection, brain hemorrhage, congenital deformity, injury, lameness, mineral deficiency, neurological problem, and unknown causes.

pected causes of mortality, with $48.1 \%(26 / 54)$ of the farmer-suspected causes being confirmed by postmortem examination. None of the deaths due to septicemia $(0 \%, 0 / 5)$ or starvation or dehydration $(0 \%, 0 / 4)$ were correctly identified by farmers. Approximately half of the deaths that were attributed to gastrointestinal disorders $(56.0 \%, 14 / 25)$ and disbudding-related injury $(44.4 \%, 4 / 9)$ were successfully identified by farmers. In addition, farmers indicated that 16 kids died from suffocation; however, postmortem examination confirmed that only $18.8 \%(3 / 16)$ of these kids suffocated, whereas the others died of underlying issues, such as gastrointestinal disorders, septicemia, and starvation or dehydration. This highlights the benefit of submitting dead kids for postmortem examination; accurately determining cause of death will allow for appropriate intervention strategies to be initiated to reduce kid mortality.

Previous research on mortality in goat kids has focused on the collection of surveillance or cross-sectional data. Although these approaches are useful, they rely on voluntary submissions of carcasses for postmortem examination or the results reflect mortality at a point in time. One of the main strengths of the current study is that a longitudinal study design was implemented. Thus, a large, defined cohort of kids, across multiple commercial dairy goat farms, was monitored from birth for survival over time, and causes of death were confirmed by postmortem examination. Overall, mortality varied between farms, with 1 farm recording no deaths, and 2 farms losing more than $20 \%$ of their enrolled kids. More than $90 \%$ of kid deaths occurred before weaning, 
which suggests that interventions need to be targeted to the preweaning period.

\section{ACKNOWLEDGMENTS}

This research was generously supported by the New Zealand Ministry of Business, Innovation and Employment (Wellington, New Zealand) and Dairy Goat Cooperative NZ (Hamilton, New Zealand). The authors gratefully acknowledge the efforts of the farmer participants, veterinarians (Ali Cullum, Alan Julian, and Elyssa Barnaby), and AgResearch Limited technicians and students, especially Sam Juby, Amanda Turner, and Briar Murphy.

\section{REFERENCES}

Adcock, S. J. J., and C. B. Tucker. 2018. The effect of disbudding age on healing and pain sensitivity in dairy calves. J. Dairy Sci. 101:10361-10373. https://doi.org/10.3168/jds.2018-14987.

Ameh, J. A., G. Egwu, and A. Tijjani. 2000. Mortality in sahelian goats in Nigeria. Prev. Vet. Med. 44:107-111. https://doi.org/10 .1016/S0167-5877(99)00108-7.

Awemu, E. M., L. N. Nwakalor, and B. Y. Abubakar. 1999. Environmental influences on preweaning mortality and reproductive performance of Red Sokoto does. Small Rumin. Res. 34:161-165. https://doi.org/10.1016/S0921-4488(99)00058-9.

Bauman, C. A., A. Jones-Bitton, P. Menzies, J. Jansen, and D. Kelton. 2016. Paratuberculosis on small ruminant dairy farms in Ontario, Canada: A survey of management practices. Can. Vet. J. 57:523-530.

Buddle, B. M., M. Herceg, M. J. Ralston, H. D. Pulford, K. R. Millar, and D. C. Elliott. 1988. A goat mortality study in the southern North Island. N. Z. Vet. J. 36:167-170. https://doi.org/10.1080/ 00480169.1988.35523.

Burgstaller, J., T. Wittek, and G. W. Smith. 2017. Invited review: Abomasal emptying in calves and its potential influence on gastrointestinal disease. J. Dairy Sci. 100:17-35. https://doi.org/10 $.3168 /$ jds.2016-10949.

de Vries, M., E. A. M. Bokkers, T. Dijkstra, G. van Schaik, and I. J. M. de Boer. 2011. Invited review: Associations between variables of routine herd data and dairy cattle welfare indicators. J. Dairy Sci. 94:3213-3228. https://doi.org/10.3168/jds.2011-4169.

Dennler, M., I. Carrera, K. Beckmann, J. Ritz, M. Rütten, and P. R. Kircher. 2014. Imaging diagnosis - Conventional and functional magnetic resonance imaging of a brain abscess in a goat. Vet. Radiol. Ultrasound 55:68-73. https://doi.org/10.1111/vru.12050.

Gautam, M. 2012. Epidemiological Study of Removals in New Zealand Dairy Goats. Master of veterinary studies thesis, Massey University, Palmerston North, New Zealand.

Gebrelul, S., L. S. Sartin, and M. Iheanacho. 1994. Genetic and nongenetic effects on the growth and mortality of Alpine, Nubian and crossbred kids. Small Rumin. Res. 13:169-176. https://doi.org/10 .1016/0921-4488(94)90093-0.

Hempstead, M. N., J. R. Waas, M. Stewart, V. M. Cave, and M. A. Sutherland. 2018a. Evaluation of alternatives to cautery disbudding of dairy goat kids using behavioural measures of post-treatment pain. Appl. Anim. Behav. Sci. 206:32-38. https://doi.org/10 .1016/J.APPLANIM.2018.05.035.

Hempstead, M. N., J. R. Waas, M. Stewart, G. Zobel, V. M. Cave, A. F. Julian, and M. A. Sutherland. 2018b. Pain sensitivity and injury associated with three methods of disbudding goat kids: Cautery, cryosurgical and caustic paste. Vet. J. 239:42-47. https://doi.org/ 10.1016/j.tvjl.2018.08.004.

Husain, S.S., P. Horst, and A.B.M.M. Islam. 1995. Effect of different factors on pre-weaning survivability of Black Bengal kids. Small Rumin. Res. 18:1-5.
Marshall, T. S. 2009. Abomasal ulceration and tympany of calves. Vet. Clin. North Am. Food Anim. Pract. 25:209-220. https://doi.org/ 10.1016/j.cvfa.2008.10.010.

Massimini, G., V. Mastellone, D. Britti, P. Lombardi, and L. Avallone. 2007. Effect of passive transfer status on preweaning growth performance in dairy goat kids. J. Am. Vet. Med. Assoc. 231:18731877.

McConnel, C. S., F. B. Garry, J. E. Lombard, J. A. Kidd, A. E. Hill, and D. H. Gould. 2009. A necropsy-based descriptive study of dairy cow deaths on a Colorado dairy. J. Dairy Sci. 92:1954-1962. https://doi.org/10.3168/jds.2008-1505.

Molaei, M. M., A. Mostafavi, R. Kheirandish, O. Azari, and M. Shaddel. 2015. Study of disbudding goat kids following injection of clove oil essence in horn bud region. Vet. Res. Forum 6:17-22.

Ortiz-Pelaez, A., D. G. Pritchard, D. U. Pfeiffer, E. Jones, P. Honeyman, and J. J. Mawdsley. 2008. Calf mortality as a welfare indicator on British cattle farms. Vet. J. 176:177-181. https://doi.org/ 10.1016/j.tvjl.2007.02.006

Perez-Razo, M. A., F. G. Sánchez, and C. H. Meza. 1998. Factors affecting kid survival in five goat breeds. Can. J. Anim. Sci. 78:407411.

Pugh, D. G., and A. N. Baird. 2012. Sheep and Goat Medicine. 2nd ed. Elsevier Saunders, Maryland Heights, MO.

Ramírez-Bribiesca, J. E., J. L. Tórtora, L. M. Hernández, and M. Huerta. 2001. Main causes of mortalities in dairy goat kids from the Mexican plateau. Small Rumin. Res. 41:77-80. https://doi .org/10.1016/S0921-4488(01)00191-2.

Sanford, S. E. 1989. Meningoencephalitis caused by thermal disbudding in goat kids. Can. Vet. J. 30:832

Scholtens, M. R., R. Smith, S. R. Lopez-Lozano, N. Lopez-Villalobos, D. Burt, L. Harper, M. Tuohy, D. G. Thomas, A. J. Carr, D. I Gray, P. Tozer, and N. M. Schreurs. 2017. Brief Communication: The current state of the New Zealand goat industry. Proc. N.Z. Soc. Anim. Prod. 77:164-168.

Snyman, M. A. 2010. Factors affecting pre-weaning kid mortality in South African Angora goats. S. Afr. J. Anim. Sci. 40:54-64. https: //doi.org/10.4314/sajas.v40i1.54128.

Thompson, K. G., R. S. Bateman, and P. J. Morris. 2005. Cerebral infarction and meningoencephalitis following hot-iron disbudding of goat kids Cerebral infarction and meningoencephalitis following hot-iron disbudding of goat kids. N. Z. Vet. J. 53:368-370. https:/ /doi.org/10.1080/00480169.2005.36578.

Thomsen, P. T., K. Dahl-Pedersen, and H. E. Jensen. 2012. Necropsy as a means to gain additional information about causes of dairy cow deaths. J. Dairy Sci. 95:5798-5803. https://doi.org/10.3168/ jds.2012-5625.

Turkson, P. K. 2003. Lamb and kid mortality in village flocks in the coastal savanna zone of Ghana. Trop. Anim. Health Prod. 35:477490.

Urie, N. J., J. E. Lombard, C. B. Shivley, C. A. Kopral, A. E. Adams, T. J. Earleywine, J. D. Olson, and F. B. Garry. 2018. Preweaned heifer management on US dairy operations: Part V. Factors associated with morbidity and mortality in preweaned dairy heifer calves. J. Dairy Sci. 101:9229-9244. https://doi.org/10.3168/jds .2017-14019.

USDA. 2010. Reference of Goat Management Practices in the United States, 2009. USDA, Washington, DC.

USDA. 2017. Goat and Kid Predator and Nonpredator Death Loss in the United States, 2015. USDA-APHIS-VS, CEAH. Fort Collins, CO, \#724.0417.

Vaatstra, B. 2018. Calf diarrhoea. VetScript October:52-55.

Vatn, S., M. A. Tranulis, and M. Hofshagen. 2000. Sarcina-like bacteria, Clostridium fallax and Clostridium sordellii in lambs with abomasal bloat, haemorrhage and ulcers. J. Comp. Pathol. 122:193200. https://doi.org/10.1053/jcpa.1999.0363.

Wäsle, K., A. Pospischil, M. Hässig, C. Gerspach, and M. Hilbe. 2017. The post-mortem examination in ruminants and its possible benefit to ruminant clinical medicine. J. Comp. Pathol. 156:202-216. https://doi.org/10.1016/j.jcpa.2017.01.003. 